\title{
DE LA INVALIDACIÓN OBJETIVISTA A LA ANULACIÓN PERSONAL. EL POTENCIAL CLÍNICO DE UNA EPISTEMOLOGÍA ASERTIVA
}

\author{
FROM OBJECTIVIST INVALIDATION TO PERSONAL DENIAL. \\ THE CLINICAL POTENTIAL OF AN ASSERTIVE EPISTEMOLOGY
}

\author{
María Luján Christiansen* \\ Departamento de Filosofía, Universidad de Guanajuato, \\ Guanajuato - México. \\ Recibido enero de 2019/Received January, 2019 \\ Aceptado marzo de 2019/Accepted March, 2019
}

\begin{abstract}
RESUMEN
En este artículo, se propondrá un abordaje de las relaciones interpersonales en contextos de maltrato emocional, las cuales serán caracterizadas como "depredadoras" desde una perspectiva sistémica que toma una metáfora ecológica como punto de partida. En primer lugar, se delimitará el denominado "patrón relacional depredador", el cual se despliega en esquemas interaccionales diversos. Luego, se establecerá la distinción entre las modalidades epistemológicas que sostienen dicho patrón (epistemología arrogante y epistemología complaciente), mostrando sus diferencias con una epistemología asertiva desde la cual dicho patrón puede cuestionarse y deconstruirse. Asimismo, se exhibirá un conjunto de combinaciones epistemológicas que pueden articularse en una relación diádica y se ofrecerán algunos ejemplos de las denominadas "distorsiones cognitivas, emocionales y pragmáticas" que redundan en los mapas que validan los ecosistemas sociales depredadores. Finalmente, se plantearán algunas ideas acerca del potencial clínico-terapéutico que el ejercicio de reflexión epistemológica supone para el campo interdisciplinar de la salud mental.
\end{abstract} Asertividad.

Palabras Clave: Ecologías depredadoras, Epistemología objetivista, Epistemología complaciente, Distorsiones cognitivas,

\begin{abstract}
In this article, an approach to interpersonal relationships in contexts of emotional abuse will be proposed, which will be characterized as "predatory" from a systemic perspective that takes an ecological metaphor as a starting point. In the first place, the so-called "predatory relational pattern" will be delimited, which is deployed in diverse interactional schemes. Then, the distinction between the epistemological modalities that sustain this pattern (arrogant epistemology and complacent epistemology) will be established, showing its differences with an assertive epistemology from which said pattern can be questioned and deconstructed. Likewise, a set of epistemological combinations that can be articulated in a dyadic relation will be exhibited and some examples of the so-called "cognitive, emotional and pragmatic distortions" will be offered, resulting in maps that validate the predatory social ecosystem. Finally, some ideas about the clinical-therapeutic potential that the exercise of epistemological reflection supposes for the interdisciplinary field of mental health will be presented.
\end{abstract}

Key Words: Predatory ecologies, Objectivist epistemology, Complacent epistemology, Cognitive Distortions, Assertiveness. 


\section{INTRODUCCIÓN}

En el marco de la ecología, la depredación es un tipo de interacción en la que un individuo de una especie animal (el depredador) caza a otro individuo (la presa) para subsistir. Estos roles son intercambiables, ya que el mismo individuo puede ser depredador de algunos animales y a su vez presa de otros. En esta trama, hay un individuo que es beneficiado (el depredador) y otro que es perjudicado (la presa), pasando la energía en el sentido presa a depredador.

Usando esta metáfora biológica en el ámbito de las relaciones interpersonales, puede decirse que existen ecosistemas de relaciones en los cuales se observan recurrentes actos que bien pueden ser considerados como "depredadores" (Colomer, 2011) ${ }^{1}$. Tal ecosistema reproduce de manera coordinada conductas altamente estereotipadas, incluso automatizadas, y fuertemente enlazadas. Para quien lo observa externamente, el ecosistema opera como una coreografía social en la que puede visualizarse incluso un cierto "estilo relacional". Quien participa en esa performance, tiende a percibir únicamente fragmentos o episodios, en lugar de secuencia y tramas: no repara en el enlace conector de las acciones de cada miembro de la relación. Por ello, la depredación (que es el desenlace de un proceso) no se percibe como resultado de una escalada en la que se ha participado activamente, sino como un padecimiento perpetrado unilateralmente por el depredador. Para tal fin, la posibilidad de relatar lo acontecido en términos de "víctima" y "victimario" viene como anillo al dedo. La epistemología lineal-descomposicional proporciona una serie de dispositivos útiles para la construcción de explicaciones monocausales y simplificadoras que dividen el campo en "causa" y "efecto" en un sentido unidireccional. De allí a la traducción moral del problema solo resta un paso. En breve, se podrá entonces hablar de "culpables" e "inocentes". Sin embargo, estas descripciones episódicas que se utilizan como ladrillos de las explicaciones amurallantes, sólo representan una visión parcial del problema. Cuando se pone el foco sobre los ecosistemas sociales en los cuales tales coreografías ocurren, la visión cambia: lo que observamos se parece más a una "película" que a una fotografía.

A continuación, se explorará con mayor profundidad el patrón relacional depredador. Seguidamente, se aludirá a ciertas herramientas epistémicas que nutren las ecologías sociales promotoras de dichas interacciones. Finalmente, se indicarán algunas propuestas relevantes para el área de la epistemología clínica.

\section{CARACTERÍSTICAS DEL PATRÓN RELACIONAL DEPREDADOR}

Las metáforas son recursos útiles para ampliar nuestra comprensión de procesos abstractos. Sin embargo, no deben tomarse al pie de la letra, ya que su función es más que nada heurística. Teniendo eso en cuenta, retornemos a la metáfora de la depredación para vislumbrar mejor sus características más distintivas:

- Comencemos por mencionar que, desde la óptica del depredador, el otro es visto como fagocitable, aunque habitualmente, en relaciones de largo aliento, no será observado como algo a devorar de manera definitiva. Dado que nos estamos refiriendo a una depredación que se da en el orden de lo simbólico, aquí se presenta una diferencia muy importante con respecto a la depredación animal, a saber: que la presa puede ser vista como re-fagocitable, por lo cual podría buscarse que en el acto depredador no sea totalmente aniquilada (garantizando así su disponibilidad futura).

- En la función predatoria hay un objetivo autocentrado, una propensión a extraer de su presa aquello de lo cual el depredador cree carecer. Por ello la elección de su objeto no está orientada a captar al más débil, sino al que, desde su percepción, posee ciertas características que, por alguna razón, el depredador evalúa como valiosas y ventajosas.

- La depredación requiere de un sigiloso monitoreo de los movimientos de la presa, por lo cual el tiempo y la paciencia son variables muy importantes para detectar y anticipar las reacciones de la presa. La cercanía y la proximidad son, en tal sentido, caldo de cultivo para potenciales intentos de depredación.

- Una peculiar estrategia para la perpetuación del acto depredador es que la presa no se vea a sí misma como presa, y que el depredador no se muestre a sí mismo como depredador. Por ello el camuflaje es una condición indispensable. Su enmascaramiento puede adquirir formatos distintos, en un continuo que va desde lo más sutil (como la seducción) hasta lo menos sutil (como el acoso). 
- Otra estrategia importante es la de generar, en la presa, actitudes de dependencia que faciliten la fagocitosis; a mayor dependencia, mayor automatización depredadora. Existen diversos mecanismos que aumentan la dependencia, como lo es, por ejemplo, el aislamiento social de la presa: al separarla de su red de apoyo, pierde las posibilidades de que la depredación pueda ser externamente evidenciada, cuestionada o evitada. Para asegurar ese aislamiento, es menester controlar cada movimiento, incluso, si es posible, a nivel del deseo.

- Para reafirmar su potencia, el depredador procurará controlar sin ser controlado; para ello, mostrará conductas erráticas y cambiantes, logrando ser mucho más impredecible que la presa y sumiendo a ésta en una incertidumbre desequilibrante. El depredador intentará, incluso, que su voz sea internalizada por la presa, y que sus opiniones pesen como certezas. En este punto, la presa muy probablemente mostrará ya una autoestima diezmada, traducida en sensaciones de indefensión personal, adormecimiento y parálisis, viéndose impedida de ensayar vías de interrupción de las conductas aniquiladoras recibidas.

- La depredación relacional a la cual nos estamos refiriendo - que opera, como se dijo, sobre un nivel simbólico/afectivo-, degrada el sentido de autonomía, individualidad y diferenciación. Al ser tratada como un objeto satisfactor, la presa es desontologizada. Su ser es un "ser para".

- La "danza" interaccional se ejecuta bajo una lógica que tiene como motor la metáfora de la relación como una competencia. En ese marco, una discusión, por ejemplo, es vislumbrada como una confrontación bélica, una guerra en la que afloran dos posibilidades, según la posición que se ocupe: si se está en una posición inferior, se la evita; si se está en una posición superior, se la promueve. Si se la evita, el conflicto estalla hacia adentro ("implosión emocional"). Si se la promueve, estalla hacia afuera ("explosión emocional"). En cualquier caso, se adoptan roles y funciones adecuados a tal cosmovisión ofensiva: el otro es un enemigo, al que hay que resistir o vencer mediante alianzas, coaliciones o cualquier estrategia que asegure la victoria $o$, al menos, la supervivencia.
- El depredador tiene grandes limitaciones para conectarse emocionalmente consigo mismo y con el otro. Vive la relación como un juego de estrategia, buscando tener el mayor control posible de sus movimientos para lograr el éxito calculado. Si hay que camuflarse, se camufla. Si hay que dar la apariencia de empatía o altruismo, también lo hace (en la medida en que eso constituye un medio para alcanzar un fin que le conviene). De hecho, cuanto más enmascare su plan táctico, más oculta quedará su contracara relacional. Se moverá en el terreno interpersonal como si este fuera un gran tablero de ajedrez donde las personas son meras piezas que ubica a su antojo y conveniencia, y por las que no siente ni compasión, ni empatía, ni remordimientos por el daño que les haya podido infligir. No obstante, actuará con total y despiadada hipocresía si es necesario (Colomer, 2011). Bajo el lema de que la realidad es amenazante y de que uno tiene que garantizar su propia supervivencia, ha perdido su capacidad de resonar afectivamente con el otro y de verlo como un igual. Por ello mismo evitará la intimidad emocional, ya que implica una estrechez en la cual sus flaquezas y vulnerabilidades podrían quedar al descubierto (dado que la depredación tiene, en quienes la practican, una historia particular). Se supone que, en una relación depredadora, la frágil debe ser la presa, y nunca a la inversa.

- En la depredación el control es fundamental, por lo cual hay una preocupación por mantener rígidamente el orden útil al acto de depredar. El cambio supone una dosis de incertidumbre atemorizante. Ante una crisis, el depredador puede sentirse paralizado, dado el cambio de esquema; si no encuentra rápidamente la forma de recuperar el control, puede intentar buscar a alguien que cargue con las decisiones para después criticarlas.

- Desde una apreciación externa, el depredador puede verse como una persona que se dice humilde pero que se desenvuelve con un orgullo desmedido y aires de arrogancia. Para disfrazar su grandilocuencia, puede esgrimir causas nobles que justifican su egoísmo: el sacrificarse a sí mismo por el bien de su familia, por ejemplo. Hay todo un aprendizaje de acorralamiento, violencia 
pasiva y agresión solapada que va puliendo a lo largo del tiempo, incluso muchas veces desde la infancia. Por otra parte, por debajo de esa narcisista valoración del sí mismo, puede haber un profundo sentimiento de inferioridad al que intenta compensar (Colomer, 2011). Por lo tanto, la ambivalencia puede ser un rasgo muy recurrente en su vida social.

- En el ámbito cotidiano, el depredador muy frecuentemente tiende a querer acumular aquello que, dentro de su grupo, le otorga prestigio, reconocimiento y poder. El dinero es, en este punto, un asunto importante. Lo puede anhelar para alimentar su grandiosidad, pero también para manipular a los demás. Por ello, aunque posea mucho, puede querer siempre más, y aun así comportarse como un avaro. Su propensión a la depredación puede verse desplegada en sus modos de ganar el dinero, ya que tenderá a utilizar todas las estratagemas que estén en su mano, tanto legales como ilegales; siempre, en este caso, que pueda burlar la ley y/o las consecuencias de sus actos poco escrupulosos (Colomer, 2011). También codiciará herencias y legados, tanto si tiene derecho a ellas como si no, que tratará de conseguir mostrándose muy amable, servicial y seductor con quien pueda ofrecérselas (Colomer, 2011).

- La coreografía depredadora induce a altos niveles de dependencia mutua entre los participantes ("co-dependencia"); ambos ocupan roles complementarios (no hay un depredador sin alguien dispuesto a ser apresado).

- La depredación como forma de la relación puede adquirir diferentes configuraciones. Una de ellas es la denominada "perseguidor-perseguido", también conocida como "hostigador-hostigado", o "acosador-acosado". En casos como este, el depredador mantiene con la presa un vínculo en el cual esta última constituye una fuente de seguridad única o primaria. El depredador alcanza un estado base de tranquilidad a través del otro (aunque esa tranquilidad está mechada con la ansiedad que produce el hecho de sentir que la propia calma depende de la presencia fagocitable del otro, y no de sí mismo). Esto puede sumirlo en estados de desesperación cuando el otro le hace dudar de su (trágica) disponibilidad. Para lograr la cercanía que tanto se requiere de la presa, apelará a tácticas cognitivas, emocionales y pragmáticas que usará de forma sugestiva o manipulatoria. Por ejemplo, puede recurrir a chantajes, berrinches, silencios punitivos (Ley del hielo), espionaje y persecución, acusaciones, manifestaciones de posesividad, celos y control. En realidad, tras su ostentosa fachada de fortaleza, se asoma un ser vulnerable que, ante la ausencia del otro, se muestra "emocionalmente hambriento". Otra posible configuración depredadora se da cuando se asumen roles de "rescatista"-rescatado", o "salvador-salvado". El acto depredador adquiere el formato de "ayuda", pero es una ayuda que solapa intenciones de vigilancia, sojuzgamiento e intrusión en las decisiones de la presa. Otra configuración posible, y recurrente, es la de "adulador-adulado", en la que predominan conductas de seducción basadas en una falsa sobrevaloración de algún aspecto del otro. El rol "victimista" también podría ser una forma de atraer a la presa, en especial cuando esta última ostenta un rol empático exagerado.

\section{Tabla 1.}

Comparación sobre dos de los Trastornos de Personalidad incluidos en el DSM-V.

\begin{tabular}{|c|c|}
\hline $\begin{array}{l}\text { Trastorno de la personalidad narcisista } \\
301.81 \text { (F60.81) }\end{array}$ & $\begin{array}{l}\text { Trastorno de la personalidad } \\
\text { dependiente } 301.6 \text { (F60.7) }\end{array}$ \\
\hline $\begin{array}{l}\text { Patrón dominante de grandeza (en la fantasía o } \\
\text { en el comportamiento), necesidad de admiración } \\
\text { y falta de empatía, que comienza en las primeras } \\
\text { etapas de la vida adulta y se presenta en diversos } \\
\text { contextos, y que se manifiesta por cinco (o más) } \\
\text { de los hechos siguientes: } \\
\text { 1. Tiene sentimientos de grandeza y } \\
\text { prepotencia (p. ej., exagera sus logros y talentos, } \\
\text { espera ser reconocido como superior sin contar } \\
\text { con los correspondientes éxitos). } \\
\text { 2. Está absorto en fantasías de éxito, poder, } \\
\text { brillantez, belleza o amor ideal ilimitado. } \\
\text { 3. Cree que es "especial" y único, y que } \\
\text { sólo pueden comprenderle o sólo puede } \\
\text { relacionarse con otras personas (o instituciones) } \\
\text { especiales o de alto estatus. } \\
4 \text {. Tiene una necesidad excesiva de } \\
\text { admiración. } \\
5 \text {. Muestra un sentimiento de privilegio (es } \\
\text { decir, expectativas no razonables de tratamiento } \\
\text { especialmente favorable o de cumplimiento } \\
\text { automático de sus expectativas). } \\
6 \text {. Explota las relaciones interpersonales (es } \\
\text { decir, se aprovecha de los demás para sus } \\
\text { propios fines). } \\
7 \text { Carece de empatía: no está dispuesto a } \\
\text { reconocer o a identificarse con los sentimientos } \\
\text { y necesidades de los demás. } \\
8 \text {. Con frecuencia envidia a los demás o } \\
\text { cree que éstos sienten envidia de él. Muestra } \\
\text { comportamientos o actitudes arrogantes, de } \\
\text { superioridad. }\end{array}$ & $\begin{array}{l}\text { Necesidad dominante y excesiva de que le } \\
\text { cuiden, lo que conlleva un comportamiento } \\
\text { sumiso y de apego exagerado, y miedo a la } \\
\text { separación, que comienza en las primeras } \\
\text { etapas de la edad adulta y está presente en } \\
\text { diversos contextos, y que se manifiesta por } \\
\text { cinco (o más) de los hechos siguientes: } \\
\text { 1. Le cuesta tomar decisiones cotidianas } \\
\text { sin el consejo y la tranquilización excesiva de } \\
\text { otras personas. } \\
\text { 2. Necesita a los demás para asumir } \\
\text { responsabilidades en la mayoría de los ámbitos } \\
\text { importantes de su vida. } \\
3 . \quad \text { Tiene dificultad para expresar el } \\
\text { desacuerdo con los demás por miedo a perder } \\
\text { su apoyo o aprobación. (Nota: No incluir los } \\
\text { miedos realistas de castigo.) } \\
4 \text {. Tiene dificultad para iniciar proyectos o } \\
\text { hacer cosas por sí mismo (debido a la falta de } \\
\text { confianza en el propio juicio o capacidad y no } \\
\text { por falta de motivación o energía). } \\
5 \text {. Va demasiado lejos para obtener la } \\
\text { aceptación y apoyo de los demás, hasta el } \\
\text { punto de hacer voluntariamente cosas que le } \\
\text { desagradan. } \\
6 . \quad \text { Se siente incómodo o indefenso cuando } \\
\text { está solo por miedo exagerado a ser incapaz de } \\
\text { cuidarse a sí mismo. } \\
7 . \quad \text { Cuando termina una relación estrecha, } \\
\text { busca con urgencia otra relación para que le } \\
\text { cuiden y apoyen. Siente una preocupación no } \\
\text { realista por miedo a que lo abandonen y tenga } \\
\text { que cuidar de sí mismo. }\end{array}$ \\
\hline
\end{tabular}

Fuente: elaboración propia. 
- Habría que añadir que, el depredador, en su rol narcisista, no tiene parejas sino suplementos: la dependencia emocional de la presa es, en tal sentido, su cómodo almohadón sobre el cual reposar. Hipersensible a la crítica, el narcisista "no aguanta nada", mientras que el dependiente emocional "aguanta todo". Estos roles son, por ello, fácilmente ensamblables y adheribles. En el Manual Diagnóstico y Estadístico de los Trastornos Mentales (DSMV), de la Asociación Psiquiátrica Americana (American Psychiatric Association, 2014), el trastorno narcisista de la personalidad y el trastorno de la personalidad por dependencia aparecen bajo la codificación (Tabla 1).

Ahora bien, a pesar del abrumador protagonismo de la perspectiva psiquiátrica anquilosada en la "industria del DSM", estas clasificaciones no otorgan herramientas para poder comprender la organización de roles dentro de una ecología depredadora. Tampoco dan cuenta de la densidad epistemológica que envuelve dicha ecología y que convalida mapas claramente parasitarios. Para ello se requiere de una mirada sistémica. Revisemos, entonces, tales aspectos.

\section{ECOLOGÍA DEPREDADORA}

La depredación no puede ocurrir fuera de una ecología que la favorezca (así como una planta no puede germinar en cualquier hábitat, sino en aquel que le ofrece las condiciones adecuadas a sus características). Por lo tanto, no depende de los individuos aisladamente considerados, sino de un equilibrio de factores que - para bien o para mal- la mantienen vigente. Uno de los más importantes componentes de ese ecosistema son las creencias, descripciones, explicaciones y relatos que los mismos participantes se cuentan acerca de la relación.

Un aspecto que no debe subestimarse es que hablar de un depredador no es hablar de una persona, sino de un rol. Desde dicho lugar, se ejerce una función pedagogizante sobre la relación: el depredador le enseña a la presa cómo son las cosas. Inocula en el marco de creencias de esta última la idea de que el depredador posee la verdad y el sentido de rectitud de las acciones propias y ajenas. Pretende que su vara de medir sea la que el resto del mundo use. No compartirla sitúa al otro en el camino del error. Como contrapartida, la presa (que tampoco es una persona, sino un rol) se autodevalúa y se autoanula. Esto hace falta subrayarlo: no sólo es anulada por el depredador, sino que la presa participa en esa anulación. El depredador le quita un poder que, al mismo tiempo, ella cede.

Acerca de esto hay que agregar que el depredador no actuará de manera abiertamente dominante. Al contrario: mediante acotaciones, correcciones tenues, gestos disimulados, miradas, sonrisas displicentes, insinuaciones, comparaciones, medias verdades y cualquier otro tipo de artilugio, sembrará sobre la presa una duda constante acerca de sí misma, aludiendo especialmente a sus puntos flacos, que bien ha conocido a través de la perspicaz inspección de sus mapas y movimientos (Colomer, 2011). Esta actitud resulta epistemológicamente agresiva de parte del depredador, y epistemológicamente sumisa de parte de la presa. Evidentemente, una ecología relacional como esta no se caracteriza por propiciar una asertividad epistemológica, desde la cual pudieran evidenciarse las distorsiones cognitivas que reinan en una relación depredadora. Revisemos los posicionamientos epistemológicos con los cuales se trazan los itinerarios interpersonales.

\section{EPISTEMOLOGÍA ARROGANTE, EPISTEMOLOGÍA COMPLACIENTE Y EPISTEMOLOGÍA ASERTIVA}

En referencia al campo de las relaciones interpersonales, puede resultar fértil considerar a las epistemologías en los siguientes términos:

1. Epistemología Arrogante (estilo agresivo)

2. Epistemología Complaciente (estilo sumiso)

3. Epistemología Asertiva (estilo autorreflexivo)

A partir de ellas, pueden darse combinaciones diferentes dentro de una relación interpersonal. Pero, antes de avanzar, detengámonos por un momento en la noción de "epistemología". Recordemos la definición propuesta por Bateson (1979) "Epistemología es la forma en cómo los organismos o agregados de organismos conocen, piensan y deciden" (p. 228). A partir de tal premisa, podemos inferir que todos tenemos una epistemología, aunque no reflexionemos sobre ella ni la apliquemos de manera consciente. Podría decirse que cada uno de nosotros portamos una epistemología personal y espontánea. 


\subsection{Epistemología Arrogante}

Una epistemología arrogante es la que está montada sobre el objetivismo, es decir, sobre la pretensión de que existen razones concluyentes para sostener un punto de vista, evidenciadas de manera neutral, imparcial y pura.

El objetivismo tiene como núcleo una máxima de lógica binaria considerada incuestionable, según la cual "Dos explicaciones distintas de la misma situación no pueden ser acertadas. Si una es correcta, su opuesta debe estar necesariamente equivocada". ¿Por qué "necesariamente" equivocada? Porque, por principio de tercero excluido (pilar de la lógica clásica, junto con la ley de identidad y la de no- contradicción), cuando dos juicios se oponen, uno debe ser verdadero, y el otro falso, quedando excluida una tercera posibilidad. El lado agresivo de este principio radica en la invalidación de aquellas posiciones que no embonan en la versión defendida como "verdadera"; si esta última se impone como "verdad", se la considerará como una resolución cerrada y sellada: el convencimiento se hará forzoso y el punto de vista del Otro quedará anulado. Así, el depredador perpetra, sobre el Otro, una suerte de epistemicidio, al hacerlo desaparecer como sujeto capaz de tener un saber válido. Pero ese "ninguneo" no es sólo de su conocimiento sino de su persona: no se lo sitúa (ni se lo trata) en condiciones de horizontalidad: no es un "igual", ya que carece del conocimiento necesario para pensar del modo correcto. Ahora, la devaluación de las razones del Otro implica, a su vez, la desconfirmación del Otro como sujeto diferente: tal como lo expresó el sociólogo Boaventura de Sousa Santos "el Otro es menos porque sabe menos, y sabe menos porque es menos". (Santos, 2014, p. 21-66)

Entre los participantes de una conversación depredadora, no se cumple el "principio de co-presencia radical" (Santos, 2014, p. 21-66), que supondría que los interlocutores se reconozcan mutuamente como simultáneos y contemporáneos en condiciones iguales (es decir, sin que existan razones para clasificar a uno en términos de progreso y al otro en términos de retraso). El otro no es visto como una fuente de saber nиеvo (ni siquiera como fuente de saber). $\mathrm{Al}$ argumentar en contra del depredador, este podría interpretar esa disidencia argumental como ignorancia, como deslealtad, como traición, como instigación y como muchas otras cosas, menos como auténtica expresión de alteridad y autonomía de pensamiento. Lo que esperará, en cambio, son autovalidaciones vanidosas, obtenidas tras haber excomulgado a aquellos que desistieron de sus intentos de colonización epistemológica. La arrogancia neutralista del depredador expresa una manera de creer, desear, sentir y actuar bajo el mecanismo de un desprecio activo por todo aquello que no pertenece al espacio de la propia validación. Inflado de jactancia objetivista, el depredador se maneja con un exceso de autoafirmación que se complementa con un exceso de devaluación de lo que no encaja en su encorsetado marco de conocimiento; no acepta más que meros confirmadores dóciles y tiende a promover cierto sectarismo social entre quienes encuentra convalidación y adulación, en lugar de cuestionamiento y escepticismo.

$\mathrm{Su}$ arrogancia neutralista pone sobre la mesa una forma de pensamiento conservadora, que acata lo que Carlos Pereda (1999) denomina la "regla de la desmesura": "siempre es bueno más de lo mismo (y nada de lo otro)" (p. 14). Hay, en tal actitud, una especie de blindaje selectivo e invisibilizado, ya que el punto de observación adoptado no se presenta abiertamente como preferencia, sino como "imparcialidad". Las premisas con las cuales edifica sus mapas están dotadas del valor de axiomas que funcionan como verdades autoevidentes. Por tanto, el depredador se adjudica a sí mismo el estatus de un representante de "obviedades" y "sobreentendidos": defiende sus creencias a capa y espada, porque las trata en tanto espejo de cómo las cosas SON. Al conversar con su presa, no busca un aprendizaje o un ensanchamiento del campo explicativo, de las ideas y de las prácticas, sino que persigue frenéticamente la homogeneización del pensamiento desde una postura directiva (Top-down). No sólo espera que el otro reconozca su error y abdique en su favor, sino que debería hacerlo amablemente, es decir, dejándose persuadir, seducir, colonizar, y si es posible, mostrando gratitud.

En esta ecología relacional gobernada por el objetivismo, el Otro no es Otro, sino prolongación del punto de vista del depredador (quien, a su vez, es amo y esclavo de una "voz única" que se repite compulsivamente como eco de sí misma).

En el intercambio conversacional entre depredador y presa, no hay apertura para que se formen nuevas comprensiones, sino una forma de comunicación estática, jerárquica y acabada, que 
no produce ni conduce a significados novedosos conjuntamente construidos.

En otras palabras, no ocurre lo que Bajtín (1975/1981) entiende como "polifonía", ese momento en que una multiplicidad de voces independientes, no fundidas entre sí y totalmente válidas, afloran en el transcurso de un proceso de habla y escucha que evoluciona sincronizadamente, en un entrelazamiento de respuesta, anticipación y contestación que está vivo, que es recíproco, que va y viene.

En el diálogo polifónico hay múltiples centros de subjetividad, o voz y agencia, sin que ninguno de ellos sea dominante; constituye un tipo de proceso comunicativo que, además de intelectual, es emocional y creativo. En el encuentro dialógico hay inocencia: "los hablantes se permiten a sí mismos estar presentes y vulnerables en un momento vivenciado y sentido, y participan en una experiencia nueva y común que aún cuando es compartida sigue siendo inexorablemente polisémica" (Olson, Laitila, Rober, \& Seikkula, 2012, p. 1-15).

Por otra parte, y como lo indicara Bateson (1976), el acto de enunciar opera en dos niveles: comunica un contenido (el mensaje transmitido verbalmente) y comunica a su vez la forma en que debe ser interpretado lo dicho (ello depende de la relación que se tenga con el interlocutor, y se expresa tácitamente, con lenguaje postural, cadencia, timbre, tono de voz, etcétera; es una comunicación sobre la comunicación, o, lo que es lo mismo: una metacomunicación). Así, el hablante queda posicionado en el mismo instante en que pronuncia su idea. Recíprocamente, el destinatario del mensaje también queda posicionado al escuchar (ya que hay diversas clases de escucha). En el caso de las relaciones depredadoras, tanto el depredador como la presa han quedado posicionados de forma tal que la argumentación es interpretada desde ese horizonte de sentido objetivista y epistemicida (aunque el depredador luego podrá explicar "objetivamente" su éxito, bajo pretexto de que la verdad siempre triunfa). Lejos del aprendizaje multiversal que se abre en un auténtico espacio dialógico, el depredador objetivista se queda intacto, extasiado de sí mismo, pero sólo (como Narciso). El depredador conversa en un vacuo soliloquio, va por su mundo relacional monologando, aunque crea que a todos convence y manipula (lo cual sólo lo consigue con sus presas). Su andar bien podría rememorar la petulancia del que detenta un conocimiento objetivo. Nietzsche afirmaba: "Si pudiéramos comunicarnos con la mosca, llegaríamos a saber que también ella navega por el aire poseída de ese mismo pathos, y se siente el centro volante de este mundo" (Nietzsche, 1873/1996, p. 17).

\subsection{Epistemología Complaciente}

La epistemología complaciente es el reverso de la epistemología arrogante. No hay una sin la otra. Esto, que podría parecer difícilmente comprensible desde una perspectiva ajena a una ecología depredadora, es posible en gran medida por un potente conjunto de distorsiones cognitivas, emocionales y pragmáticas desde las cuales la "presa" construye un mapa relacional que convalida el rol interaccional que ocupa (por desfavorable que sea). A continuación, se examinan algunos ejemplos prototípicos de tales distorsiones:

- Abstracción selectiva: se le presta atención a un solo aspecto o detalle de la situación, omitiendo el contexto, las circunstancias y los aspectos que no son asimilables en el marco interpretativo del observador.

- Pensamiento dicotómico: las experiencias son codificadas como todo o nada, buenas o malas, un completo éxito o un fracaso total.

- Inferencia a la mejor explicación: se extraen conclusiones de una situación a partir de indicios que se toman como fundamentos. $\mathrm{La}$ explicación es arbitraria, pero se la presenta como certera.

- Sobregeneralización: a partir de incidentes aislados, se lleva a cabo una nomologización (es decir, se habla como si la generalización tuviera el peso de una ley natural).

- Magnificación y Minimización: se tiende a exagerar lo negativo o positivo de una situación, un suceso o una cualidad propia.

- Personalización: se traslada a la relación y se toma como personal aquello que otros atribuyen a sucesos exteriores, sin que existan suficientes pruebas para llegar a esa conclusión.

- Visión de túnel: se ve sólo aquello que se ajusta a la propia expectativa.

- Explicación autoconfirmadora: se construye una explicación desde un cierto sesgo (imperceptible) y lo observado como producto de dicho sesgo se toma como evidencia confirmadora de la veracidad de la explicación.

- Rotulación global: consiste en poner etiquetas globales sin tener en cuenta otros matices. 
- Lectura de la mente: asumir que uno tiene el poder de adivinar, con seguridad, lo que el otro está pensando (y viceversa).

Véase el siguiente caso: en una pareja heterosexual donde ambos tienen 62 años y 38 de casados, el esposo siempre ha tomado las decisiones importantes acerca de cómo debe usarse el dinero que él gana. Nunca han hablado al respecto, aunque eso ha supuesto que su esposa se vea impedida de realizar múltiples actividades que requieren de gastos (como, por ejemplo, ir a visitar a su familia a su pueblo). Esto les ha generado conflictos reiterados, los cuales se expresan en lenguaje de quejas, críticas y reclamos. No obstante, la relación permanece con esa organización económica, sostenida por un enjambre de creencias enquistadas en el mapa epistemológico que sostiene la danza relacional que comparten. Por ejemplo, ella da por sentado que empleo y trabajo son lo mismo, por lo cual concluye que solo trabaja él (dado que ella no está empleada). Desde esta abstracción selectiva, las labores domésticas que ella realiza no son vistas como "trabajo". También considera que ella no debe opinar porque no aporta nada a la economía del hogar (su visión dicotómica no le permite pensar que el arreglo fáctico que ellos tienen no es ni totalmente bueno ni totalmente malo, sino con ventajas y desventajas que podrían ser analizadas y cuestionadas). Dado que él recurrentemente se ofusca cuando hay gastos extras (y le pone etiquetas globales como "desprendida", "abusiva", "gastalona", "malcriada"), ella "infiere" que el problema que ella tiene en el uso del dinero debe venir desde su familia de origen, donde no le enseñaron a administrarlo correctamente. Ella concluye que esta explicación debe ser cierta, ya que recuerda que su padre también le recriminaba a su madre que malgastaba el dinero de la familia. Asume, así, que existe una conexión causal directa y simple entre infancia y destino. Acepta, además, que "el que paga manda" (y eso lo tiene como una ley incuestionable, ya que los hombres que ha conocido a lo largo de su vida se han adjudicado ese privilegio). A pesar de las repetidas ocasiones en que debe enfrentarse a situaciones cotidianas sin pedirle dinero a su marido, ella siente que el esfuerzo que él hace por ganar el dinero es inmensamente superior al que ella hace por acomodarse a un estilo de vida modelado por la carencia y por la falta de ingresos propios. Magnifica los logros de él y minimiza las invisibilizadas batallas de ella. De hecho, no puede verse como alguien que ha tenido la suficiente creatividad como para poder afrontar día con día pequeños retos (por ejemplo, ella logró terminar la escuela básica mediante el apoyo que consiguió en un programa de educación de adultos en los que pudo pagar una cuota mediante labores comunitarias de tejido y costura). Comúnmente él habla con gran desdén de la gente que es una "carga" para los demás, y ella siente que es una insinuación dirigida hacia ella (personaliza un comentario dirigido a un público indeterminado). Ella no puede verse fuera del estereotipo que concibe como "natural y normal" que sea el hombre quien tome las decisiones importantes. Así, no espera mucho más de él, ni tampoco espera mucho más de ella misma.

Esta visión en túnel no abre posibilidades sobre otras formas de arreglo convivencial que les ayudara a evitar las discusiones que mantienen habitualmente. Además, aunque nunca se lo ha preguntado, ella "sabe" que su marido se irritaría muchísimo si ella le pidiera administrar el dinero en ciertas áreas (aunque en verdad, esa conclusión está basada en una adivinación que ella anticipa dándola por hecho, pero nunca se lo planteado abierta y claramente). En conclusión, su rol de dependencia económica está fincado sobre una dependencia emocional y pragmática mantenida no sólo con respecto a su esposo, sino a su mapa cognitivo. De allí que ella acepte resignadamente su rol de presa, como un desenlace inexorable. A pesar de su frustración diaria, no le falta techo y comida, lo cual para ella es una evidencia de que su mapa cognitivo no puede estar equivocado.

\subsection{Epistemología Asertiva}

La noción de Asertividad proviene del latín asserere, asser tum (Aserción), y significa $a_{\text {atrmar }}^{2}$. Aquí se propondrá la idea de que una epistemología es asertiva cuando afirma sin negar, es decir, cuando valida un cierto mapa cognitivo, emocional y decisional sin anular un mapa distinto. En este sentido, se vuelve altamente esclarecedor el posicionamiento batesoniano según el cual "el mapa no es el territorio", que cimentó las bases para adoptar actitudes pluralistas con respecto al conocimiento. Pueden existir mapas alternativos que resulten orientadores respecto al territorio al que se quiere llegar. El concepto de equifinalidad se vuelve entonces muy fructífero, ya que implica que un sistema viviente puede llegar a un mismo estado final desde distintas condiciones iniciales y 
por distintos caminos. Esto quiere decir que $a$ ) un sistema puede alcanzar la misma meta siguiendo itinerarios diferentes en sus procesos organísmi$\cos ; b)$ los resultados a los que llega el sistema, en el sentido de alteración del estado al cabo de un periodo de tiempo, no están determinados ni por las condiciones iniciales ni por la naturaleza de los procesos. Por lo tanto, idénticos resultados podrían tener orígenes distintos, y viceversa.

Si se piensa el caso anterior a la luz del concepto de equifinalidad, podría apreciarse que, por ejemplo, una esposa puede alcanzar el objetivo de "tener techo y comida" bajo otras condiciones ecosistémicas. Es decir, donde ella avizora su situación como "inevitable precio a pagar" por asegurarse techo y comida, existen muchos otros mapas, itinerarios y caminos posibles que la llevarían al mismo lugar (y quizás varios de esos caminos pudieran ser mejor transitables, más disfrutables y emocionalmente menos costosos para ella).

Desde una epistemología asertiva, uno "Dice lo que piensa y piensa lo que dice" (Efran, Lukens, \& Lukens, 1994). Este axioma contiene, en su primera parte (decir lo que se piensa), una valoración de la autoafirmación (lo cual es un aspecto necesario de la asertividad); en su segunda parte (pensar lo que se dice), este principio alude a una actitud de respeto a la diferencia, basada en el uso de un lenguaje alejado de la pretensión objetivista de pensamiento único.

Ahora bien, si se tiene en cuenta que la mayor parte del tiempo nuestras conversaciones discurren sobre ideas, esquemas, mapas y epistemologías no reflexionadas (sea arrogante o sumisa), cabe preguntarse por el efecto subyugante que tales epistemologías arrastran. Desde hace algún tiempo, Cecchin, Lane y Ray (2003) comprendieron el incalculable poder de adhesividad que tienen las ideas en los ecosistemas relacionales, así como su capacidad performativa (creadora de "realidades"). Al respecto, señalaban que

una lealtad excesiva a una idea específica hace que la persona no sea responsable de las consecuencias morales inherentes a ella. Si sobreviene un desastre, el responsable no será el individuo, sino la Idea (con "I" mayúscula) que ha comandado la acción. (Cecchin, Lane, \& Ray, 2003, p. 26).
Cabría apuntalar esta afirmación aclarando que esa lealtad excesiva a "la Idea" (cualquiera sea) tiene una carga afectivo-emocional dentro de relaciones determinadas. No son simples programaciones cognitivas acopiadas, sino parte de nuestro sentido de pertenencia a ciertos ecosistemas sociales. La rigidización mental se alimenta de (y alimenta a) la rigidización emocional y pragmática. Debe considerarse que ideas, emociones y acciones se influyen recíprocamente: existen entre ellas relaciones de recursividad (todas son, simultáneamente, causa y efecto: lo que se piensa influye sobre lo que se siente, que a su vez influye sobre lo que se hace, que a su vez influye sobre lo que se piensa, y así concomitantemente). De modo que, cuando un individuo ya se ha aferrado a un mapa fijo, y está persuadido de que ése, y sólo ese posicionamiento, es el correcto, considera que todas las potenciales formas de observar la situación quedan suprimidas "por default". Ya sea que lo exteriorice o que lo albergue en su foro interno, las razones que tal sujeto esgrima en su favor tendrán, para él, un carácter irrenunciable, constrictivo. Y ello ocurrirá bajo estados emocionales y decisionales específicos.

Cuando impera una epistemología arrogante-agresiva, nos encontraremos con un sujeto que, al sentirse en posesión de "la idea objetivamente verdadera", se dispondrá a dar la lucha por ella, porque lo que está bajo escrutinio no es únicamente su idea, sino su integridad epistémica. Si se le niega la razón, entenderá el cuestionamiento como una muestra de estupidez, de insulto, de ofensa o de maltrato, reaccionando en consecuencia. A tal punto podría su idea elevarse a dogma y regla de conducta, que una amenaza a ella podría ser interpretada como una amenaza a su persona.

Las distorsiones cognitivas que enumerábamos como facilitadoras de una epistemología complaciente-sumisa, operan, también en una epistemología agresiva. En una epistemología asertiva, sin embargo, también se conoce, se piensa, se siente y se actúa desde distorsiones o sesgos, pero la gran diferencia es que existe, en el observador, una consciencia autocrítica y autorreflexiva acerca de tales prejuicios. Se acepta que, como epistemólogos naturales, somos cartógrafos natos; se acepta también que nuestros mapas son los que han podido ser (es decir, los que hemos podido construir a la luz de los múltiples condicionamientos de las ecologías en las cuales vivimos), 
pero se admite también que esos mapas pueden cambiar: la flexibilidad epistemológica permite fluir con el inevitable cambio vital. Nuestros mapas se acomodan a "las realidades", que son nuestros mapas. En tal sentido, y retornando al caso de las ecologías depredadoras, habría que recalcar que la depredación es una forma de interacción que no se concibe sin mapas de depredación. Y, si los mapas se pueden rehacer, los ecosistemas relacionales también. Nuevos mapas rehacen ecosistemas en los que se rehacen nuevos mapas.

\section{EPISTEMOLOGÍAS Y ESTEREOTIPOS DE GÉNERO}

¿De qué dependen nuestras epistemologías personales? Podría indicarse que las experiencias de socialización primaria y secundaria son decisivas, o que las vivencias más tempranas son determinantes, o que hunden sus raíces en cuestiones inconscientes, o que todo ello influye, entre otros muchos factores. Sobra decir que la respuesta es compleja y que, dada la equifinalidad, también es incierta. Algo que sí se querría señalar aquí (sin presunción de responder al interrogante) es que tanto la epistemología agresiva como su contraparte, la sumisa, se han estereotipado en base al género. Así, la epistemología agresiva se ha asociado a la masculinidad, y está encarnada en una matriz de valores culturales que exaltan la competencia, el rigor, el éxito, la verdad, el progreso, la objetividad y la razón; mientras que la epistemología complaciente se ha vinculado con la feminidad, y se la ha fundido con valores como la subordinación, el servilismo, la abnegación, la concesión, la entrega, la emocionalidad, la irracionalidad, la docilidad y la subjetividad.

Esta esterotipificación es por demás simplificante, pero muy potente como motor de expectativas culturales acerca de cómo se debe ser y de qué roles se deben desear ocupar dentro de una ecología relacional. Estos estereotipos construyen mitologías sociales que sirven de material para muchos mapas en muchas epistemologías "espontáneas".

Si pensamos en la formación de una nueva ecología relacional, como ocurre cuando inicia una relación de pareja, asistimos a una combinación "dancística" nueva: la unión de dos epistemologías personales, que podrían ser arrogantes; o la unión de dos epistemologías complacientes, o la unión de una epistemología arrogante y (o contra) una epistemología complaciente. De acuerdo con los estereotipos de género, se esperaría que una pareja prototípica (que equivale a decir heterosexual) encarne la última combinación (epistemología arrogante-agresiva enquistada en el hombre, epistemología complaciente-sumisa enquistada en la mujer).

Sabemos, empero, que estos mapas (y su parafernalia narrativa) han sido severamente cuestionados en la posmodernidad, denunciándose todo tipo de opresión sexista y depredadora en tal forma de organización relacional. Podría decirse, entonces, que una epistemología asertiva contribuiría a la erosión de los "mapas últimos" impuestos agresivamente y aceptados sumisamente. Pero sería un error defender una epistemología asertiva en términos de destrucción de las epistemologías arrogante/complaciente, ya que precisamente lo que se pretende es ensanchar el campo de posibilidades y quitarle peso, así, a lo supuestamente "inevitable". Ni biología es destino, ni cultura es destino. Eso significa una renuncia a la pretensión de corregir necesariamente a las ecologías que se organizan según ideales tradicionales sin que sus participantes lo vivan como problemático. Las ecologías no son, en sí mismas, ni buenas ni malas, ya que el juicio valorativo les compete a quienes viven las consecuencias de los mapas que las sostienen.

Pero, entonces, accederíamos, por esta vía de la combinación epistemológica, a la diversificación de configuraciones relacionales y de ecologías interpersonales variadas. Se presentan ahora, en una Tabla 2, las posibles combinaciones epistemológicas en una relación diádica (como lo es la relación de pareja, o la relación entre terapeuta y consultante, o la relación entre terapeuta y supervisor):

\section{Tabla 2.}

Combinaciones epistemológicas en una relación diádica.

\begin{tabular}{ll}
\hline \multicolumn{1}{c}{ Miembro 1 } & \multicolumn{1}{c}{ Miembro 2 } \\
\hline Epistemología Arrogante & Epistemología Arrogante \\
Epistemología Arrogante & Epistemología Complaciente \\
Epistemología Arrogante & Epistemología Asertiva \\
Epistemología Complaciente & Epistemología Arrogante \\
Epistemología Complaciente & Epistemología Complaciente \\
Epistemología Complaciente & Epistemología Asertiva \\
Epistemología Asertiva & Epistemología Arrogante \\
Epistemología Asertiva & Epistemología Complaciente \\
Epistemología Asertiva & Epistemología Asertiva \\
\hline
\end{tabular}

Fuente: elaboración propia. 


\section{EL POTENCIAL CLÍNICO DE LA EPISTEMOLOGÍA}

Se le adjudica a Epicuro el siguiente fragmento: "Vana es la palabra del filósofo que no remedia ningún sufrimiento del hombre, porque tal como no es útil la medicina si no suprime las enfermedades del cuerpo, tampoco la filosofía, si no suprime los sufrimientos del alma" (como se citó en Usener, 1887, p. 169). Explorando las bondades terapéuticas de la reflexión epistemológica para el ámbito de la salud mental, habría que recordar que, en 1977, Rabkin propuso crear una nueva especialidad terapéutica, que sugirió denominar "epistemología clínica" (Keeney, 1987, p. 42). La intención subyacente es la de realizar mapas de mapas (el terapeuta traza un mapa epistemológico del mapa epistemológico del consultante), siempre teniendo en consideración que el mapa del terapeuta es susceptible de ser cuestionado desde un orden epistemológico más abstracto. El terapeuta deviene entonces en un constructor epistemológico que, al igual que en la relación de pareja, combina su epistemología con la del consultante. Así, si este último ordena los sucesos de su vida desde una epistemología arrogante, y el terapeuta lo escucha desde una epistemología igualmente arrogante, reforzará el objetivismo agresivo del punto de vista del consultante (la relación terapéutica se convertirá en una lucha de depredadores). Si, en cambio, lo escucha desde una epistemología sumisa, el espacio terapéutico devendrá complaciente, dejando inalterado el mapa cognitivo, emocional y pragmático que causó el problema por el cual ha consultado al terapeuta. Pero, si la escucha es realizada desde una epistemología asertiva, se abrirá un abanico de posibilidades sobre el cómo reordenar, re-narrar y re- significar esa construcción rigidizada a la cual se le llama "autobiografía" (y que es contada como si fuera una "historia oficial"). No se trataría, entonces, de "corregir" un mapa, sino de "perder la inocencia" con respecto a los mapas vigentes, y de inventar mapas nuevos, que muevan y saquen al consultante del rol que perpetra en su indeseable ecología relacional. Esta ampliación de la observación de los mapas que ocurre en la relación entre consultante y terapeuta se repite también en la relación entre terapeuta y supervisor clínico. Este último puede contribuir a que el terapeuta "pierda la inocencia" con respecto al mapa que ha construido sobre la problematica del consultante. Siempre es posible imaginar un "observador del observador", y un "mapa del mapa": el terapeuta que observa al consultante, el supervisor que observa al terapeuta, el colegio profesional que observa al supervisor, y así sucesivamente.

\section{REFLEXIONES FINALES}

Hay, en la epistemología, un potencial clínico-terapéutico de profundo calado (afirmación que nos obligaría a recordar los ya olvidados orígenes socráticos de la psicoterapia). La reflexión epistemológica ayuda a deshacer nudos existenciales porque los mapas cognitivos, antes de reflexionarlos, los sentimos y los actuamos, los padecemos o los gozamos. Por lo tanto, el ejercicio de revisión crítica de nuestros saberes no puede quedar limitado únicamente a los filósofos. Dicho ejercicio es indispensable para fecundar nuestro acervo de mapas explicativos y cambiar los roles sociales que nos resultan agobiantes o insoportables. La filosofía no es un saber sin supuestos, sino, por el contrario, un saber que se sabe impregnado de supuestos, y entonces se autoexamina. Ciertamente, ha tenido pretesiones de Objetividad, Verdad y Absoluto, volviéndose arrogante y agresiva. Pero ha sido desde la filosofía misma que dichas pretensiones han sido denunciadas y cuestionadas. La objeción a la epistemología arrogante y a la epistemología sumisa constituyen una forma de ataque a dichas pretensiones: el arrogante se cree poseedor de una Verdad Absoluta y Objetiva; el sumiso cree que dicha verdad existe, pero que no la posee). La epistemología asertiva no solo no avala tales pretensiones, sino que las considera típicas de ecologías sociales depredadoras. Todo encuentro interpersonal (diádico, triádico u otro) es un encuentro de epistemologías, y el posicionamiento asertivo se abre a la inagotable diversidad cartográfica de la experiencia humana; no le teme a las distorsiones cognitivas, porque entiende que el problema no es tenerlas, sino ignorarlas. $\mathrm{La}$ actitud asertiva permite afirmar el propio mapa y, aún así, aceptar la posibilidad de mapas alternos que lleven a nuevos paisajes. 


\section{Referencias}

Alberti, R., \& Emmons, ML. (1978). Your Perfect Right: A Guide to Assertive Behavior. San Luis Obispo, California: Impact.

American Psychiatric Association, Kupfer, D. J., Regier, D. A., Arango López, C., Ayuso-Mateos, J. L., Vieta Pascual, E., \& Bagney Lifante, A. (2014). DSM-5: Manual diagnóstico y estadístico de los trastornos mentales. Madrid: Editorial Médica Panamericana.

Bakhtin, M. (1975/1981). The dialogic imagination. Texas, United States of America. University of Texas: University of Texas Press.

Barr, K.N. \& Quinsey, V.L. (2004). Is psychopathy a pathology or a life strategy? Implications for social policy. En C. Crawford \& C. Salmon (Eds.), Evolutionary Psychology, Public Policy, and Personal Decisions (pp. 293-317). Mahwah, United States: Lawrence Erlbaum Associates Publishers.

Bateson, G. (1976). Pasos para una ecología de la mente. Buenos Aires: Ediciones Carlos Lohl.

Bateson, G. (1979). Mind and Nature. A Necessary Unit. New York: United States. Dutton.

Blackburn, R. (1988). On moral judgements and personality disorders. The myth of psychopathic personality revisited. $\mathrm{Br}$. J. Psychiatry, 153, 505-12. doi: 10.1192/bjp.153.4.505

Book, A., Quinsey V., \& Langford D. (2007). Psychopathy and the perception of affect and vulnerability. Criminal Justice Behav., 34, 531-544. doi: 10.1177/0093854806293554

Book, A. \& Quinsey V. (2004). Psychopaths: Cheaters or warriorhawks? Pers. Individ. Differences, 36, 33-45. doi: 10.1016/ S0191-8869(03)00049-7

Brewer, G., Hunt D., James G., \& Abell L. (2015). Dark triad traits, infidelity and romantic revenge. Pers. Individ. Differences, 83,122-127. doi: 10.1016/j.paid.2015.04.007

Camp, J,. Skeem J,. Barchard K,. Lilienfeld, S., \& Poythress, N. (2013). Psychopathic predators? Getting specific about the relation between psychopathy and violence. J. Consul. Clin. Psychol., 81, 467-480.doi 10.1037/a0031349

Cecchin, G., Lane, G., \& Ray, W. (2003). Irreverencia: una estrategia de supervivencia para terapeutas. Barcelona: Paidós.

Colomer, N. (2011). Depredadores Emocionales. Barcelona: Editorial Planeta.

Declercq, F., Willemsen, J., Audenaert, K., \& Verhaeghe, P. (2012). Psychopathy and predatory violence in homicide, violent and sexual offenses: Factor and facet relations. Legal Criminol. Psychol., 17, 59-74. doi: 10.1348/135532510X527722

Efran, J., Lukens, D., \& R. Lukens (1994). Lenguaje, estructura y Cambio. La estructuración del sentido en psicoterapia. Barcelona: Gedisa.

Eliot, G. (1859/1989). Adam Bede en The Macmillan Dictionary of Quotations. Nueva York: Macmillan.

Hare, R. (2001). Psychopaths and their nature: Some implications for understanding human predatory violence. En A. Raine \& J. Sanmartin (Eds.), Violence and Psychopathy (pp. 5-34). New York: Kluwer.

Jones, D. (2014). Predatory personalities as behavioral mimics and parasites: Mimicry-deception theory. Perspect. Psychol. Sci., 9, 445- 451.doi: 10.1177/1745691614535936
Jurjako, M. \& Malatesti, L. (2016). Instrumental rationality in psychopathy: Implications from learning tasks. Philos. Psychol., 29, 717-731. doi: 10.1080/09515089.2016.1144876

Keeney, B. (1987). La estética del cambio. Barcelona: Paidós.

Kennett, J. (2010). Reasons, emotion, and moral judgment in the psychopath. En L. Malatesti \& J. McMillan (Eds.), Responsibility and Psychopathy: Interfacing Law, Psychiatry and Philosophy (p. 17). London: Oxford University Press.

Lazarus, A. (1966). Behavior rehearsal vs. Non-directive therapy vs. Advice in effectiong behavior change. Behavior Research and Therapy, 4, 209-212.

Levi, M., Nussbaum, D., \& Rich, J. (2010). Neuropsychological and personality characteristics of predatory, irritable, and nonviolent offenders: Support for a typology of criminal human aggression. Criminal Justice Behav., 37, 633-655. doi: $10.1177 / 0093854810362342$

McEllistrem, J. (2004). Affective and predatory violence: A bimodal classification system of human aggression an violence. Aggression Violent Behav., 10,1-30. doi: 10.1016/j. avb.2003.06.002

Meloy, J. R. (1997). Predatory violence during mass murder. $J$. Forensic Sci., 42, 326-329.

Meloy, J. (2006). The empirical basis and forensic application of affective and predatory violence. Aust. NZ J. Psychiatry, 40, 539-547. doi: 10.1080/j.1440-1614.2006.01837.x

Meloy, J. (2012). Predatory violence and psychopathy. En H. Hakkanen-Nyholm \& J. Nyholm (Eds.), Psychopathy and Law (pp. 159-175). London: Wiley and Song.

Meloy, R., Book, A., Hosker-Field, A., Methot-Jones, T., \& Roters, J. (2018). Social, Sexual, and Violent Predation: Are Psychopathic Traits Evolutionarily Adaptive? Violence and Gender, 5(3). doi: 10.1089/vio.2018.0012

Nietzsche, F. (1873/1996). Sobre Verdad y Mentira en sentido extramoral. Madrid: Tecnos.

Olson, M., Laitila, A., Rober, P., \& Seikkula, J. (2012). Del Monólogo al Diálogo en una Sesión de Terapia de Pareja: Investigación Dialógica del Cambio desde el Punto de Vista de los Terapeutas. Fam. Proc., 51, 1-15.

Pereda, C. (1999). Crítica de la razón arrogante. Distrito Federal. México:Taurus-Alfaguara.

Rasmussen, K. \& Boon S. (2014). Romantic revenge and the Dark Triad: A model of impellance and inhibition. Pers. Individ. Differences, 56, 51-56. doi: 10.1016/j.paid.2013.08.018

Salter, A. (1949). Conditioned Reflex Therapy. New York: Starus and Giroux.

Santos, B. \& Meneses, M. P. (2014). Epistemologías del Sur Perspectivas. Madrid: Akal.

Sinnott-Armstrong, W. (2014). Do psychopaths refute internalism? En T. Schramme (Ed.), Being Amoral: Psychopathy and Moral Incapacity (187-208). Cambridge: MIT Press.

Usener, G. (1887). Epicurea. Leipzig: Tuebner.

Wheeler, S., Book, A., \& Costello, K. (2009). Psychopathic traits and perceptions of victim vulnerability. Criminal Justice Behav., 36, 635-648. doi: 10.1177/0093854809333958

Wolpe, J. (1958/1977). La práctica de la Terapia de Conducta. México: Trillas. 


\section{Notas al final}

1 La noción de "depredación emocional" está estrechamente ligada a otros conceptos estudiados por las ciencias sociales, la criminología y las ciencias de la salud mental, tales como "vampirismo emocional", "psicopatía integrada" o "personalidad maquiavélica”. Consultar Meloy, R., Book, A., Hosker-Field, A., Methot-Jones, T. y Roters, J. (2018); Camp, Skeem, Barchard, et al. (2013); Hare (2001); Jones (2014); McEllistrem (2004); Meloy (1997); (2006); (2012); Blackburn (1988); Hare (2001); Jones (2014); McEllistrem (2004); Meloy (2006); Barr, Quinsey (2004); Book, Quinsey, Langford (2007); Barr, Quinsey (2004); Book AS, Quinsey VL. (2004); Brewer, Hunt, James, Abell (2015); Declercq, Willemsen, Audenaert, Verhaeghe (2012); Jurjako, Malatesti (2016); Kennett (2010); Levi, Nussbaum, Rich (2010); Rasmussen, Boon (2014). Sinnott-Armstrong (2014); Wheeler, Book, Costello (2009).

$2 \quad$ La noción de "asertividad" tuvo sus orígenes en los trabajos de Andrew Salter (1949), Joseph Wolpe (1958) y Arnold Lazarus (1966). Posteriormente, fueron apareciendo sucesivas contribuciones, como la de Alberti y Emmons (1978) y la revista ASSERT: The Newsletter of the Assertive Behavior, en Estado Unidos. Aunque existe una enorme diversidad de definiciones, hay que resaltar la coincidencia que la señalan como una competencia o habilidad social, a través de la cual el sujeto asertivo puede expresar y defender su interés sin dañar ni anular los intereses del interlocutor. En este artículo, sin embargo, la nocion de asertividad será empleada para hablar de cierta epistemología, y no de la conducta individual. 